\title{
Transmittibility of Ear Resistance to European Corn Borer in Sweet Corn Testcrosses and Resistance Stability
}

\author{
Mary S. Joyce ${ }^{1}$ and David W. Davis ${ }^{2}$ \\ Horticultural Science Department, University of Minnesota, St. Paul, MN 55108 \\ Additional index words. insect resistance, vegetable breeding, biocontrol, Zea mays, Ostrinia nubilalis
}

\begin{abstract}
Concern over insecticide usage for control of European corn borer (Ostrinia nubilalis Hübner) in sweet corn (Zea mays L.) in recent years has increased the need for genetic control. Our objectives were to determine the degree of ear feeding resistance transmitted by resistant breeding lines to testcrosses and to investigate the relationship between resistance and both ear silk channel length, and infestation level. Testcrosses averaged 35\% acceptable ears compared to $7 \%$. for two commercial control hybrids and $45 \%$ for the lines per se when artificially infested at the ear tip at mid-silk at two locations. Generally, resistance in the testcrosses was closer to the resistance level of the resistant parent, indicating good combining ability for resistance. Heterosis above the resistant parent was found in 8 of 12 testcrosses. Across entries, ears having relatively longer silk channel length tended to have less damage but the relationship was not strong $\left(r_{2}=0.24\right.$, $P<0.01)$. When silk channels were artificially shortened at infestation, resistance levels were lower, but five of seven lines had a higher proportion of acceptable ears than did the control hybrid. Across increasing levels of infestation from 50 to 200 neonate larvae per ear eight of nine lines had higher resistance $(P<0.05)$ than the control.
\end{abstract}

Larvae of the European corn borer (ECB) can attack all above-ground parts of the maize plant. In sweet corn, ear damage causes the most significant loss to growers. In the north central states control typically requires three to four insecticide applications, but sometimes more than eight are necessary. Resistant cultivars could help preserve food safety, reduce environmental contamination, and reduce grower costs.

Ear-feeding resistance to the ECB is a quantitative trait with inheritance conditioned predominantly by additive effects (Grier and Davis, 1980; Lamb et al., 1994). Few sweet corn hybrids and breeding materials have been identified as resistant. Andrew and Carlson (1976) found 0 to 15 husk penetrations in artificially infested hybrids and inbreds, and ear tip damage from $0 \%$ to $100 \%$. The hybrids, 'Apache' (Davis and Grier, 1978; Davis et al., 1992) and 'More' (Davis et al., 1994), and recently released parental germplasm lines A684 su, A685 su, and A686 su (Davis et al., 1993) also have been shown to have resistance to ear feeding. Using $F_{3}$ family means, Grier and Davis (1980) calculated heritabilities of $55 \%$ to $66 \%$ for cob tunneling and $57 \%$ to $85 \%$ for kernel damage resistance.

The underlying mechanisms for ear-feeding resistance by ECB is not known. Maysin, implicated in resistance to corn earworm (Helicoverpa zea Boddie) in 'Zapalote Chico', (Waiss et al., 1979), is not effective against the ECB. 'Zapalote Chico', however, has some ear-feeding resistance to this insect (Davis and Grier, 1978). While an underlying chemical basis for resistance is possible, ear structure also might be important. A684 su, A685 su, and A686 su are characterized by a tight, narrow silk channel.

Received for publication 31 Mar. 1994. Accepted for publication 8 Aug. 1994. Published as paper 21085, Minnesota Agricultural Experiment Station, We acknowledge the assistance of David Andow and Theresa Leahy, Entomology Dept., Univ. of Minnesota, for providing larvae and suggesting protocols for field tests, and of Robert Busch, USDA/ARS, Dept. of Agronomy and Plant Genetics, Univ. of Minnesota, for counseling in data analysis. This work was funded in part by the Midwest Food Processors Association and the Blandin Foundation. The cost of publishing this paper was defrayed in part by the payment of page charges. Under postal regulations, this paper therefore must be hereby marked advertisement solely to indicate this fact.

'Former graduate research assistant.

${ }^{2}$ Professor.
Many breeding lines with some resistance tend to have a greater silk channel length than many susceptible commercial hybrids, as also do 'Apache' and 'More'.

Our objectives were 1) to determine the degree of ear feeding resistance transmitted from breeding lines to testcrosses, and 2) to evaluate the resistance of breeding lines a) when subjected to several levels of infestation, and b) with artificially shortened silk channels.

\section{Materials and Methods}

Testcross experiment. Testcrosses, with reciprocals combined, were made between six sugary (sul) Minnesota lines (96, 98, 101, $106,132,169$ ) (Table 1), varying in resistance to ear feeding, and two sul susceptible proprietary inbreds (designated as 16 and 18). The twelve test hybrids, six lines, two inbreds, the F, hybrid of the two inbreds, and a standard susceptible hybrid, 'Jubilee', were evaluated in 1989 at St. Paul and Rosemount, Minn. The experimental design was a randomized complete-block with eight replications (blocks) at each location. Single-row plots on 0.76-m centers were planted in mid-May and thinned to 10 plants at the V4 to V6 (Ritchie and Hanway, 1982) vegetative growth stages. 'Jubilee' and $16 \times 18$ were planted on three dates in each block to assure the availability of control plants comparable in developmental stage to that of the test entries at the time of artificial infestation. The first two plantings of the control hybrids were used because they were at the mid-silk stage at the time of infestation. Cultural practices were similar to those for commercial irrigated (St. Paul) and dryland (Rosemount) sweet corn.

We infested exposed silk on the primary (upper) ear of each plant with 40 to 50 neonate, laboratory-reared larvae from an aggressive colony. A' Davis inoculator was used to dispense the larvae- corn-cob meal (dry grits) mixture prepared in the rearing laboratory (Ortega et al., 1980). At St. Paul, each ear was infested after silk appearance but before silk drying. Infestation extended over several days because some plant-to-plant variation in date of silking is normal. At Rosemount, however, all ears were infested on one day, due to time and travel considerations; thus, somewhat greater precision was expected at St. Paul. At Rosemount the silks 
on some of the ears had begun to dry by the date of infestation. Following open pollination, ears at the St. Paul location were covered to prevent bird damage. At both locations an uninfested border row was planted on the outer edge of and between blocks, and a $4.5-\mathrm{m}$ border was planted at row ends.

Up to six ears per plot were hand husked at 25 to 30 days after infestation, and evaluated via a nine-point visual rating scale based on amount and location of damage on the ear (Table 2). Ears with less than $1 \%$ kernel damage (rating 1 to 3 ) at the ear tip were considered commercially acceptable for processing. Thus, the percent of ears scoring 3 or lower was used as the estimate of degree of resistance. Silk channel length from cob tip to the point where silk emerged from the ear husk tip was measured on each ear.

A general linear model (GLM) analysis of variance on percent acceptable ears per plot was calculated. Genotypes, (testcrosses, parents, and the controls) were considered a fixed variable in the model. LSD mean separation was conducted on entry means. Locations were analyzed separately due to an entry by location interaction. Heterosis for ear-feeding resistance was evaluated as departure of the testcross hybrids from their midparent. Correlation coefficients for silk channel length vs. ear damage, in addition to a GLM pooled estimate of variance, were calculated.

Shortening of silk channel length. Two field experiments were conducted at St. Paul to determine the impact of shortened silk channel on ear-feeding resistance. If resistance were solely a function of longer silk channels we reasoned that resistance would be lost when the silk channel was shortened. Treatments consisted of 1) cutting the silk channels to $5 \mathrm{~cm}$ beyond the tip of the growing cob and 2 ) cutting at the existing husk tip to remove the silkbrush, but with no definitive channel length reduction. The second treatment provided a wound surface comparable to that of the first treatment. Infestation and evaluation protocols were identical to those of the testcross experiment. Ear shoots were treated the day before infestation. In the first experiment, conducted in 1989, three resistant breeding lines $(96,98,101$ ) with silk channel lengths averaging more than $7.5 \mathrm{~cm}$ were used (Table 1); four more (80, $95,114,124)$ were added in the second experiment, conducted in 1990, and line 98 was dropped due to shortage of seed. 'Jubilee' was used as a control both years. Single-row, 1.5-m, bordered plots were planted in mid-May. Plants were grown, ear shoots were artificially infested on the silks, and ears were evaluated as described above for the testcross experiment. Plots were thinned to six plants in 1989 and to ten in 1990. The experimental design consisted of three (1989) or six (1990) breeding lines $x$ two treatments arranged in a randomized complete-block design with six replications. Following analysis of variance, a paired test was used to evaluate mean comparisons.

Infesting with different numbers of larvae. Two field experiments were conducted at St. Paul to evaluate ear-feeding resistance at infestation levels (treatments) of $\approx 50,100,150$, and 200 neonate larvae per primary ear. In 1989, four S, breeding lines $(96,98,132,169)$ (Table 1) were evaluated. Five other $\mathrm{S}_{1} \mathrm{~s}(618$, $620,621,2667,2670)$ were evaluated in 1990. 'Jubilee' and 'Prime Pak' were used as controls in 1989 and 'Jubilee' served as the control in 1990. 'Jubilee' was planted twice ('Jubilee' 1 and 'Jubilee' 2) in 1989 to ensure availability of control ears. Single-row 1.5- (1989) and 3-m (1990) plots on 0.76 and $0.91 \mathrm{~m}$ centers, respectively, were overplanted in mid-May and thinned to six plants in 1989, and to ten in 1990. Plot establishment and cultural practices were followed as described above for the testcross experiment.

A completely randomized split-block design with six replications (blocks), split by infestation level, was used. To reduce border effects from differing infestation levels, treatment rows

Table 1. Origin of European corn borer-resistant sweet corn breeding lines.

\begin{tabular}{|c|c|}
\hline $\begin{array}{l}\text { Line } \\
\text { designation }\end{array}$ & Derivation \\
\hline 80 & $\begin{array}{l}\mathrm{S}_{1} \text { from a composite created by bulking seed from } 26 \mathrm{~S}_{3} \mathrm{~s} \text { from }(\mathrm{Ia} 453 \times \mathrm{B} 52) \mathrm{S}_{6} \times \text { Ia } 453 \text { after } 2 \text { years of } 5 \% \text { to } 10 \% \text { simple mass } \\
\text { half-sib (bulk sib) selection based on ECB ear reaction. }\end{array}$ \\
\hline $95,96,98$ & $\begin{array}{l}\mathrm{S}_{1} \mathrm{~s} \text { from a composite of } \mathrm{S}_{6} \text { lines of Ia } 453 \times \mathrm{B} 52 \text { after } 5 \text { years of } 10 \% \text { to } 20 \% \text { simple mass half-sib (bulk sibbing) selection based } \\
\text { on ECB ear resistance. }\end{array}$ \\
\hline $101,106,114$ & $\begin{array}{l}S_{1} \text { s from a composite created by bulking seed from four ECB ear resistant } S_{6} \text { selections from Apache and one } S_{2} \text { from } \\
\text { Apache } x(\operatorname{Ia} 453 \times \mathrm{B} 52) \mathrm{S}_{6} \text {. }\end{array}$ \\
\hline 124 & $\begin{array}{l}\mathrm{S}_{1} \text { from }\left[\left(\mathrm{Ia} 453 \times \mathrm{B}^{2}\right) \mathrm{S}_{6} \times \mathrm{Hyb}_{7}\right] \mathrm{S}_{2} \times \mathrm{Ga} 396(6) 1-1 \text { after } 6 \text { years of } 5 \% \text { to } 10 \% \text { simple mass half-sib selection based on ECB } \\
\text { ear resistance. }\end{array}$ \\
\hline 132 & 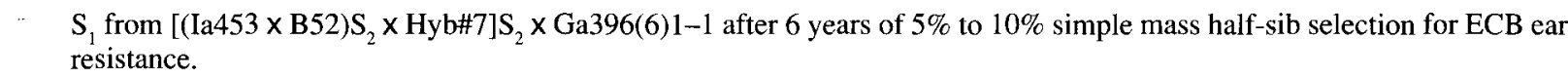 \\
\hline 169,2670 & $\begin{array}{l}\left.\mathrm{S}_{1} \text { from }\left[(\mathrm{Ia} 453 \times \mathrm{B} 52) \mathrm{S}_{6}\right] \times\left[\left((\mathrm{Ia} 453 \times \mathrm{B} 52) \mathrm{S}_{4} \times \mathrm{Ill125}\right)\right) \times\left(\mathrm{Ia} 453 \times \mathrm{B}_{52}\right) \mathrm{S}_{4}\right] \text { after } 5 \text { years of } 5 \% \text { to } 10 \% \text { simple mass half-sib } \\
\text { selection for ECB leaf-feeding and ear resistance plus hypersensitive-based resistance to common leaf rust }(\text { Puccinia sorghi). }\end{array}$ \\
\hline $618,620,621$ & $S_{3}$ s from Apache $S_{4} \times\left(\right.$ Ia $453 \times$ B52) $S_{6}$. \\
\hline 2667 & $S_{1}$ from a composite created by bulking seed from $4 S_{6}$ selections from Apache and $1 S_{2}$ from Apache $S_{4} \times\left(\operatorname{Ia} 453 \times\right.$ B52) $S_{6}$. \\
\hline
\end{tabular}

Table 2. Visual rating scale for ear resistance to the European corn borer.

1 = No damage to husks, silks or kernels

$2=$ Silk and/or husk damage only

$3=\mathrm{Up}$ to $1 \%$ of the kernels damaged at the ear tip only

$4=1 \%$ to $5 \%$ of the kernels damaged at the ear tip only

$5=6 \%$ to $10 \%$ of the kernels damaged at the ear tip only

$6=\mathrm{Up}$ to $5 \%$ of the kernels damaged at the ear tip and at the side, or at the side only

$7=6 \%$ to $10 \%$ of the kernels damaged at the ear tip and at the side, or at the side only

$8=$ Cob tunneling from the tip or shank

$9=$ More than $10 \%$ of the kernels damaged on the ear 
ere separated by two border rows, with 1.5 - and 3-m borders between blocks and at block ends, respectively. As in the testcross experiment, we infested freshly silked ear shoots with the Davis inoculator. However, before infestation we fitted the ear shoot tips with waxed paper cones to hold the larvae-grits mixture. The cones were removed the following day, and up to six ears per plot were scored for damage 15 to 20 days after infestation.

Following analysis of variance on ear damage scores, LSD mean separation was calculated for entry and infestation level. Correlations between ear damage and silk channel length, and a pooled estimated of variance were calculated to determine the relationship between silk channel length and ear damage under the various levels of infestation.

\section{Results and Discussion}

Testcross evaluation. Overall mean ear damage did not differ by location. 'Jubilee', Inbred 16 , Inbred 18 , and the hybrid $16 \times 18$ were highly susceptible, with only 1370 of the ears rated commercially acceptable (ratings 3.0), except for $16 \times 18$ at St. Paul, which had $28 \%$ acceptable ears (Table 3 ). Five Minnesota breeding lines were more resistant than 'Jubilee' $(P \leq 0.05)$ at St. Paul and all six were more resistant at Rosemount; thus, there was some entry by location effect. The breeding lines varied; with 96, 98, and 169 tending to have the greatest resistance $(39 \%$ to $75 \%$ acceptable ears) at both locations.

Ten of the twelve testcrosses were more resistant $(P \leq 0.05)$ than
'Jubilee' at Rosemount, and seven were more resistant than $16 x$ 18. However, at St. Paul only two and five testcrosses were more resistant than these two control hybrids, respectively. Generally, testcross resistance level was closer to that of the resistant parent; thus, the breeding lines tended to be good combiners. Midparent heterosis was positive for Lines 98, 101, 106, and 132 at St. Paul and for 106 and 169 at Rosemount, exceeding $100 \%$ in eight combinations (Table 3).

The breeding lines varied from 3.9 to $9.5 \mathrm{~cm}$ for mean silk channel length. Ten of the twelve testcrosses had silk channel lengths averaging $\approx 30 \%$ to $55 \%$ shorter than their resistant parent. The two exceptions, testcrosses between the short-silk-channel lines (106 and 169) and Inbred 16, equalled or exceeded Inbred 16 in silk channel length. A negative relationship $(P<0.05)$ between silk channel length and ear damage was found for crosses $101 \times 16$, $132 \times 18 ; 169 \times 16$ and $169 \times 18$, but not for the breeding lines per se (Table 3); values for $r$ were not lower than -0.35 . The pooled estimate for silk channel length on ear damage score yielded art $r^{2}$ value of 0.24 . Thus, short silk channel length was not strongly related to greater ear damage.

Effect of artificially shortened silk channel length. Both lines (genotypes) and silk channel shortening treatments resulted in differences $(P \leq 0.05)$ in percent acceptable ears each year (data not shown). Lines ranged from $40 \%$ to $86 \%$ and $73 \%$ to $78 \%$ acceptable ears from shortened vs. normal ear shoots, respectively, in 1989 compared to $27 \%$ for normal 'Jubilee' (Table 4). Although results were similar in 1990, two lines, 80 and 124, had fewer

Table 3. Parent vs. testcross comparison for degree of ear damage by European corn borer on sweet corn at St. Paul and Rosemount, Minn., and correlation $(r)$ between silk channel length and ear damage at St. Paul.

\begin{tabular}{|c|c|c|c|c|c|c|c|c|c|c|}
\hline \multirow[b]{2}{*}{ Parents/crosses } & \multicolumn{2}{|c|}{ Acceptable ears $(\%)^{2}$} & \multicolumn{2}{|c|}{ Mid-parent } & \multicolumn{2}{|c|}{ Heterosis( $(\%)$} & \multicolumn{2}{|c|}{$\begin{array}{l}\text { Silk channel } \\
\text { length }(\mathrm{cm})\end{array}$} & \multirow[b]{2}{*}{$r$} & \multirow[b]{2}{*}{$P$} \\
\hline & St. Paul & Rosemount & St. Paul & Rosemount & St. Paul & Rosemount & Range & Mean & & \\
\hline 96 & 56 & 67 & & & & & $0.0-14.0$ & 9.1 & 0.01 & 0.93 \\
\hline $96 \times 16$ & 3 & 31 & 32 & 40 & -91 & -23 & $0.0-10.2$ & 4.9 & -0.20 & 0.07 \\
\hline $96 \times 18$ & 20 & 69 & 29 & 36 & -31 & +92 & $1.3-9.5$ & 4.9 & -0.14 & 0.23 \\
\hline 98 & 39 & 75 & & & & & $2.5-14.0$ & 9.5 & 0.05 & 0.70 \\
\hline $98 \times 16$ & 49 & 34 & 24 & 44 & +104 & -23 & $0.6-8.3$ & 4.6 & -0.09 & 0.43 \\
\hline $98 \times 18$ & 67 & 40 & 21 & 40 & +219 & 0 & $0.6-10.2$ & 4.4 & -0.05 & 0.61 \\
\hline 101 & 36 & 54 & & & & & $2.5-15.2$ & 8.3 & -0.10 & 0.39 \\
\hline $101 \times 16$ & 48 & 31 & 22 & 34 & +118 & -9 & $0.0-10.2$ & 4.4 & -0.28 & 0.01 \\
\hline $101 \times 18$ & 39 & 23 & 19 & 29 & +105 & -29 & $0.0-10.2$ & 4.2 & -0.19 & 0.10 \\
\hline 106 & 28 & 21 & & & & & $0.0-14.0$ & 4.3 & -0.16 & 0.16 \\
\hline $106 \times 16$ & 69 & 25 & 18 & 17 & +283 & +47 & $1.3-15.2$ & 4.9 & 0.12 & 0.26 \\
\hline $106 \times 18$ & 27 & 15 & 15 & 13 & +80 & +15 & $0.0-7.6$ & 2.6 & 0.10 & 0.31 \\
\hline 132 & 18 & 30 & & & & & $0.0-12.7$ & 6.0 & -0.11 & 0.33 \\
\hline $132 \times 16$ & 29 & 23 & 13 & 22 & +123 & +5 & $0.0-8.9$ & 4.2 & -0.09 & 0.42 \\
\hline $132 \times 18$ & 27 & 13 & 10 & 17 & +170 & -24 & $0.0-7.6$ & 3.0 & -0.24 & 0.03 \\
\hline 169 & 69 & 64 & & & & & $0.0-10.2$ & 3.9 & -0.17 & 0.15 \\
\hline $169 \times 16$ & 25 & 61 & 39 & 39 & -36 & +56 & $0.0-7.6$ & 4.3 & -0.32 & 0.00 \\
\hline $169 \times 18$ & 11 & 73 & 36 & 34 & -69 & +115 & $0.0-7.6$ & 2.5 & -0.35 & 0.00 \\
\hline \multicolumn{11}{|c|}{ Susceptible parents } \\
\hline Inbred 16 & 8 & 13 & & & & & $2.5-12.7$ & 8.1 & -0.17 & 0.12 \\
\hline $16 \times 181$ & 28 & 8 & & & & & $1.9-11.4$ & 5.6 & 0.21 & 0.05 \\
\hline $16 \times 182$ & 12 & 6 & & & & & $0.0-8.3$ & 4.2 & -0.26 & 0.01 \\
\hline Inbred 18 & 2 & 4 & & & & & $0.0-10.2$ & 5.0 & 0.11 & 0.26 \\
\hline \multicolumn{11}{|l|}{ Control } \\
\hline Jubilee 1 & 0 & 0 & & & & & $0.0-5.1$ & 0.9 & 0.07 & 0.48 \\
\hline Jubilee 2 & 5 & 0 & & & & & $0.0-8.9$ & 1.5 & 0.04 & 0.72 \\
\hline L S D & 33 & 24 & & & & & & & & \\
\hline L S D 0.05 & 25 & 18 & & & & & & & & \\
\hline
\end{tabular}

${ }^{2}$ Ears scoring 3 or lower on the 1 to 9 visual rating scale (Table 2) for ear damage were classed as acceptable for commercial processing. 
Table 4. Percent acceptable ears, and mean silk channel length (SCL) for 'Jubilee' and for shortened and nonshortened ears of sweet corn breeding lines resistant to European corn borer.

\begin{tabular}{|c|c|c|c|}
\hline \multirow[b]{2}{*}{ Entry/treatment } & \multirow[b]{2}{*}{ Acceptable ears $(\%)^{z}$} & \multicolumn{2}{|c|}{$\mathrm{SCL} \quad(\mathrm{cm})$} \\
\hline & & Mean & Range \\
\hline \multicolumn{4}{|c|}{1989} \\
\hline 96 & 78 & 10.2 & $5.1-14.6$ \\
\hline 96 cut & 44 & 5.7 & $3.2-14.0$ \\
\hline 98 & 78 & 10.2 & $7.6-12.7$ \\
\hline 98 cut & 40 & 6.4 & $3.8-9.5$ \\
\hline 101 & 73 & 8.3 & $5.0-14.0$ \\
\hline 101 cut & 86 & 5.1 & $3.8-9.5$ \\
\hline Jubilee & 27 & 3.2 & $0.0-6.4$ \\
\hline \multicolumn{4}{|c|}{1990} \\
\hline 80 & 47 & 10.8 & $0.0-16.5$ \\
\hline 80 cut & 16 & 8.9 & $2.5-15.2$ \\
\hline 95 & 75 & 10.8 & 7.615 .2 \\
\hline 95 cut & 58 & 8.9 & $1.3-14.0$ \\
\hline 96 & 35 & 8.3 & $3.8-12.1$ \\
\hline 96 cut & 29 & 5.1 & $1.3-8.9$ \\
\hline 101 & 78 & 10.2 & 7.615 .2 \\
\hline 101 cut & 42 & 5.1 & $1.9-8.9$ \\
\hline 114 & 89 & 12.1 & $6.4-15.2$ \\
\hline $114 \mathrm{cut}$ & 69 & 10.2 & $6.4-15.2$ \\
\hline 124 & 42 & 15.2 & $8.3-19.7$ \\
\hline 124 cut & 9 & 7.6 & $3.2-13.3$ \\
\hline Jubilee & 24 & 2.5 & $0.0-5.1$ \\
\hline
\end{tabular}

'Ears scoring 3 or lower on the 1 to 9 visual rating scale (Table 2) for ear damage were classed as acceptable for commercial processing.

acceptable ears following silk channel shortening (9\% and $16 \%$, respectively) than the 'Jubilee' control (24\%). The paired t test indicated a relationship $(P=0.004)$ between increased ear damage and silk channel shortening in 1990, but not in $1989(P=0.34)$. The unexpected behavior of line 101 in 1989, in which ears with shortened silk channels had less rather than more damage, may have masked the ear damage vs. silk channel length relationship in that year.

Considerable silk channel regrowth occurred in some breeding lines. In some lines, silk channel length for cut ears was $80 \%$ to $90 \%$ of that of uncut ears (Table 4 ). We are unsure about the relative continued growth rate of cob vs. husk, following midsilk. Subsequent to silk channel length shortening to $5 \mathrm{~cm}$, we expected some cob and husk regrowth as a part of the continued normal development of the ear shoot, but the line to line differences could reflect either genotypic differences or the possibility that some lines were cut earlier in the midsilk period than others and, thus, were capable of more regrowth. Also, while lines and hybrids tend to have characteristic silk channel lengths, the length can vary considerably from year to year, with exposed ear tips occurring in some years on some genotypes.

Resistance maintained as infestation level increased. Differences for ear damage (percent acceptable ears) were found $(P \leq$ 0.01) among lines (genotypes) and infestation levels. Across levels, resistance was retained ( $P \leq 0.01)$ over the 'Jubilee' control for all breeding lines in both years (Table 5) and there was no lineby-infestation level interaction $(P>0.05)$. Lines had $54 \%$ to $77 \%$ and $55 \%$ to $94 \%$ acceptable ears in 1989 and 1990, respectively, compared to $2 \%$ to $10 \%$ for 'Jubilee'.

Level 50 resulted in less damage $(P \leq 0.01)$, as indicated by percent acceptable ears, than levels 150 and 200, but levels 100,
150, and 200 did not differ (Table 5). There was evidence that progressive increase in larval numbers at infestation resulted in some decline in number of acceptable ears, but with a definite plateauing response are between 150 and 200 larvae (data not shown). Line 98 was the most stable line in year 1, with acceptable ears decreasing from $79 \%$ to $67 \%$. Line 96 decreased from $86 \%$ to $60 \%$ acceptable ears, with 169 and $132,83 \%$ to $48 \%$, and $75 \%$ to $29 \%$ acceptable ears, respectively, compared to $31 \%$ to $0 \%$ for 'Jubilee' (data not shown). In year 2, line 2667 remained 91910 to $100 \%$ acceptable, while lines 620, 618, 621, and 2670 decreased from $92 \%$ to $83 \%, 93 \%$ to $77 \%, 89 \%$ to $66 \%$, and $77 \%$ to $39 \%$ acceptable, respectively, compared to $33 \%$ to $0 \%$ for 'Jubilee' (data not shown).

No indication of change in the relationship between ear damage and silk channel length was found in specific lines as infestation level increased. Values for $r$ tended to be low and $70 \%$ were negative, with $r^{2}$ values seldom exceeding 0.20. A pooled covariance estimate of silk channel length on damage across entries and levels showed a stronger relationship $\left(r^{2}=0.51, P<0.01\right)$. Pooled correlation estimates calculated from larger numbers of lines in our breeding program in previous years generally have provided a weak relationship ( $r=-0.17$ to -0.35 ) (Davis et al., 1992).

Infestation levels greater than 50 larvae at the ear tip are extreme, and it is not likely that natural infestations, even in epidemic years, would reach 100 to 200 larvae per ear. At the higher levels of infestation, the larvae could become cannibalistic in the silk channel. Cannibalism among borer larvae is unlikely in a natural situation, but has been observed in the rearing laboratory at the Univ. of Minnesota when levels of larvae are extremely high (Theresa Leahy, personal communication). They are particularly vulnerable after a molt, before the cuticle has hardened. Also, 
Table 5. Effect of infestation level on ear damage by European corn borer on resistant sweet corn breeding lines'.

\begin{tabular}{|c|c|c|c|}
\hline \multicolumn{4}{|c|}{ Entries across levels of infestation } \\
\hline Lines & Acceptable ears $(\%)^{y}$ & Lines & Acceptable ears $(\%)$ \\
\hline$\overline{96}$ & $77 \mathrm{a}$ & 2667 & $94 \mathrm{a}$ \\
\hline 98 & $75 \mathrm{a}$ & 620 & $88 \mathrm{ab}$ \\
\hline 169 & $63 \mathrm{ab}$ & 618 & $86 a b$ \\
\hline 132 & $54 \mathrm{~b}$ & 621 & $80 \mathrm{~b}$ \\
\hline Jubilee 1 & $9 \mathrm{C}$ & 2670 & $55 \mathrm{c}$ \\
\hline Jubilee 2 & $2 \mathrm{C}$ & Jubilee & $10 \mathrm{~d}$ \\
\hline L S D & 20 & & 13 \\
\hline
\end{tabular}

Levels of infestation across entries (lines and controls)

Level

Acceptable ears $(\%)$

\begin{tabular}{lcc}
\cline { 2 - 3 } (no. of larvae) & 1989 & 1990 \\
\hline 50 & $57 \mathrm{a}$ & $79 \mathrm{a}$ \\
100 & $42 \mathrm{ab}$ & $70 \mathrm{ab}$ \\
150 & $32 \mathrm{~b}$ & $64 \mathrm{~b}$ \\
200 & $39 \mathrm{~b}$ & $62 \mathrm{~b}$ \\
LSD $_{\text {o.o1 }}$ & 15 & 10
\end{tabular}

${ }^{2}$ Means within column followed by the same letter do not differ $(P=0.01)$.

${ }^{y}$ Ears scoring 3 or lower on the 1 to 9 visual rating scale (Table 2) for ear damage were classed as acceptable for commercial processing.

larvae might leave an ear with a high population.

Jarvis and Guthrie (1987) applied one, two, four, and eight egg masses per ear $(\approx 30$ eggs/mass $)$ to compare kernel damage in popcorn, dent corn, and sweet corn. Damage was determined by counting the number of kernels damaged, and the egg masses were not placed at the ear tip. 'Silver Queen' and 'Tahitian Hi-Sugar', the two sweet corn hybrids used, were considered susceptible, with damage ranging from 7.9 and 19.5 kernels per ear, respectively, at one egg mass, to 17.6 and 64.8 at eight egg masses. Location of damage was not considered and actual hatch of eggs per mass was not reported. In our research, ears arbitrarily were classed as acceptable if receiving up to $1 \%$ kernel damage, with damage occurring only at the ear tip. On an average hybrid ear, 1\% kernel damage would equal about five kernels. Ears having one or more kernels damaged by larval penetration into the. side or base of the ear, however, were not considered acceptable.

In conclusion, moderate ear-feeding resistance was confirmed for the several breeding lines, and most lines transmitted a significant level of resistance in testcross combination. Resistance generally was maintained when the ear silk channel was shortened, or when larval numbers were increased. While resistance levels comparable to those of the breeding lines used in this research have been shown by Bolin et al. (1993) and Hutchison et al. (1992) to have potential in reducing insecticide needs, even higher levels undoubtedly will be desirable in ECB resistance management by the sweet corn industry. The industry has long had as its goal a zero tolerance for product contamination by the ECB, and the processing sector also continues to have a strong interest in eliminating need for costly hand-trimming of ears.

\section{Literature Cited}

Andrew, R.H. and J.R. Carlson, Jr. 1976. Evaluation of sweet corn inbreds for resistance to European corn borer. J. Amer. Soc. Hort. Sci. 101:9799.

Bolin, P.C., W.D. Hutchison, and D. Davis. 1993. Dual impact of resistant hybrids and Bacillus thuringiensis for European corn borer control, p.
67-84. In: 1993 Processing crops manual and proceedings. vol. 5. Midwest Food Processors Assn., Madison, Wis.

Davis, D.W., D.A. Andow, and W. D. Hutchison. 1993. Registration of three European corn borer resistant sweet corn germplasm lines: A684 su, A685 su, and A686 su. Crop Sci. 33:1422-1423.

Davis, D., D. Andow, W. Hutchison, K. Sauter, and G. Gingera. 1992. Development of resistance in sweet corn to European corn borer, p. 6974. In: 1992 Processing crops manual and proceedings. vol. 4. Midwest Food Processors Assn., Madison, Wis.

Davis, D.W., G.R. Gingera, and D.K. Wamock. 1994. Breeding for resistance to European corn borer and other pests in sweet corn, p. 8592. In: 1994 Processing crops manual and proceedings. vol. 6. Midwest Food Processors Assn., Madison, Wis.

Davis, D.W. and S.L. Grier. 1978. Resistance of some sweet corn germplasm to second-brood European corn borer. Ann. Plant Resistance to Insects Nwsl. 4:23-25.

Grier, S.L. and D.W. Davis. 1980. Infestation procedures and heritability of characters used to estimate ear damage caused by second-brood European corn borer (Ostrinia nubilalis, Hübner) on corn. J. Amer. Soc. Hort. Sci. 105:3-8.

Hutchison, W.D., D.W. Davis, P.C. Bolin, D.W. Bartels, and V. Fritz. 1992. Alternative methods for European corn borer control and firstyear results on the impact of 1st-generation infestations on sweet corn yield and quality, p. 321-326. In: 1992 Processing crops manual and proceedings. vol. 4. Midwest Food Processors Assn., Madison, Wis.

Jarvis, J.L. and W.D. Guthrie. 1987. Ecological studies of the European corn borer (Lepidoptera: Pyralidae) in Boone County, Iowa. Environ. Entomol. 16:50-58.

Lamb, E. M., D.W. Davis, and D.A. Andow. 1994. Mid-parent heterosis and combining ability of European corn borer resistance in maize. Euphytica 72:65-72.

Ortega, A., S.K. Vasal, J. Mihm, and C. Hershey. 1980. Breeding for insect resistant maize, p. 371419. In: F.G. Maxwell and P.R. Jennings (eds.). Breeding plants resistant to insects. Wiley, New York.

Ritchie, S.W. and J.J. Hanway. 1982. How a corn plant develops. Iowa State Univ. Coop. Ext. Serv. Spec. Rpt. 48.

Waiss, A.C., B.G. Chan, C.A. Elliger, B.R. Wiseman, W.W. McMillian, N.W. Widstrom, M.S. Zuber, and A.J. Keaster. 1979. Maysin, a flavone glycoside from corn silks with antibiotic activity toward corn earworn. J. Econ. Entomol. 72:256-258. 